\title{
Research on the Current Situation and Reform Measures of Logistics Management in Small and Medium Sized Enterprises
}

\author{
Wendong Zhao \\ Department of computer and software engineering \\ Huaiyin Institute of Technology \\ Huaian, China \\ zwd_139@163.com
}

\author{
Fenfen Li \\ Department of computer and software engineering \\ Huaiyin Institute of Technology \\ Huaian, China \\ xsc6902@163.com
}

\begin{abstract}
With the rapid development of China's economy, logistics enterprises have become an important foundation for China's economic construction. Through investigation and study, this paper analyzes the current situation of the development of small and medium sized logistics enterprises in China, and puts forward the problems existing in the development of small and medium-sized enterprises and the reasons for the problems. Finally, the existing problems of the enterprise, give specific, practical and feasible suggestions and suggestions for reform. Hope that small and medium-sized logistics enterprises in the development of cooperative and mutual assistance, for the social energy efficiency, for our country's economic construction to make greater contribution.
\end{abstract}

Keywords-small and medium-sized enterprises; logistics; cooperation and mutual assistance; electronic Commerce, internet

\section{INTRODUCTION}

With the rapid development of social economy, the Internet as a platform for the development of the 21st Century, become an important milestone of the progress of science and technology, at the same time that the economic system of our country entered a new era of epoch-making, enterprise marketing mode is also quietly changed, from the traditional marketing mode to the development of e-commerce mode now, small and medium enterprises(SMEs) have embarked on the road of the development of information technology. Currently there are business-to-business BTC platform and enterprisesto-end-users of the BTB platform, through these platforms, the enterprises not only broaden the sales channels, but also reduce the cost of marketing. At present, the main factors restricting the development and cost of the network platform business activities are the development of the logistics industry and the control of the logistics cost. a meeting at the beginning of the commercial activities of the third party logistics, because of the late start, various aspects of the work are not perfect, the current business is booming, has brought unprecedented opportunities and challenges to small and medium-sized logistics enterprises ${ }^{[1]}$. Based on this, this article through the analysis of the status of the logistics of small and development of logistics industry, and combined with the characteristics of the logistics enterprises at this stage, proposed to guide the small and medium-sized logistics enterprises to the healthy development of opinions and suggestions, and hope the government to formulate a reasonable policy guidance, to establish a set of reasonable and comprehensive system structure, the incentive to carry out cooperation and mutual assistance between small and medium enterprises(SMES), reduce enterprise logistics costs for the community products, and to improve the competitiveness of enterprise products, make contribution for the economic development of our country.

\section{The DeVelopment Status of SMall AND Medium ENTERPRISES LOGISTICS}

\section{A. Research background}

In recent years, the domestic economic growth and the rapid development of Internet based business activities; the domestic logistics industry was vigorous development. Logistics has gradually become an important part of the national economic construction, the tertiary industry development as an important foundation for the national economic construction ${ }^{[2]}{ }^{[8]}$. The development of the logistics industry, mainly due to the rapid development of computer and network technology, e-commerce platform based on the WEB platform embarked on a fast lane. It is the electronic commerce platform based on Internet, consumers and businesses directly to the transaction reduce the intermediate links. On the one hand, consumers can buy goods at very low prices, while companies also get more profits.

E-commerce network sales model based on the network, which can affect the price of products are two main factors , one is the production cost of enterprise, the second is the logistics cost of sending the product to the user, therefore, the development of the logistics industry directly affect the development of the production enterprises. Logistics business is more complicated, is a multi-functional service, involving many industries, such as: transportation, warehousing, production enterprises and consumers, etc. Therefore, the development of the logistics industry can drive a number of enterprise economic developments, for which the government also attaches great importance to the development of the logistics industry. 


\section{B. Problems in logistics management of Small and Medium Enterprises}

The development of the logistics industry is more involved, in which the larger business is based on the Internet platform for electricity business; the domestic economic development has a very important significance. However, with the development of the times, the changes of the years, and compared with the developed countries, logistics cost has been in a high position, the reason, mainly in the following aspects.

\section{1) Outdate concept of enterprise product marketing}

Small and medium enterprises (SMEs) in the development process is bound to focus on economic benefits, it attaches great importance to and production related business, the late part of the marketing is not very important. The ultimate goal of each enterprise is consistent, the pursuit of high efficiency and capital accumulation. But a lot of business managers only pay attention to production costs, not the latter of the cost of marketing attention. If the modern enterprises, the importance of logistics management products, a good marketing idea, will give enterprises save a lot of marketing costs, especially the logistics cost of goods, to small and medium enterprises bring huge profits space at the same time, also to provide consumers with quality and cheap products ${ }^{[3]}$.

\section{2) Logistics management means and methods behind}

In recent years, the logistics business in the development, but the majority of small and medium enterprises in the logistics management means and methods still remain in the traditional manual management mode, not to think of how to save the cost of logistics, one of the most important reasons is that they don't have to study the logistics transportation costs accounted for the profit ratio, just a simple distribution and transport. One thought is to rely on the quantity to win.

\section{3) The lack of senior management personnel}

Logistics management process is more and more tend to be professional, which is bound to put forward higher requirements for managers ${ }^{[4]}$. Small and medium business owners only employ professionals, especially the high degree of specialization of talent; they can drive enterprises to the road of the development of information technology. However, from the results of our current survey, most of the small and medium enterprises (SMEs) in the lack of logistics professional managers, the degree of modernization is not high, so the efficiency of enterprises is not high.

\section{4) The low level of enterprise information}

With the development of computer technology and Internet technology, information technology has penetrated into every field of society, which brings convenience to the management of enterprises and people's daily life, and also improves the efficiency of production ${ }^{[5]}{ }^{66}$. Enterprises in the development process, if the smooth implementation of information technology, the integrated use of information technology, is bound to embark on the road of rapid development. But often because of small and medium business owners do not recognize the benefits of information, do not want to put more money in the information, or through a large amount of manual operation, which also determines the enterprise's cost high, the natural efficiency is not high.

\section{5) The lack of communication and cooperation between} SMEs

At present, the domestic small and medium-sized logistics enterprises in the business are independent operation, the lack of necessary cooperation. The operation of the market of freight cars, the property generally have the following conditions: large transport company owned, small and medium-size transport company owned, partnership or sole proprietorship and affiliated vehicles. The affiliated vehicle, partnership, sole proprietorship, is basically person in operation, this part accounted for most of the market. In addition, due to some companies in the management of the demand, there are still a number of transport companies owned vehicles, contracted to

Lease to the driver in the form of the situation. The current situation of property rights, market prices caused by the confusion of the system and information asymmetry, malicious competition prevails, individual owners in the possession of sources or sources of information with companies and people to suppress, get the price is the final price of the layers of exploitation (especially the return price of the vehicle, sometimes even costs is not enough) the result is the drivers violations in logistics transportation. Another situation is a more common, such as a driver in the enterprise will reach the destination of the goods, if there is no other sources of return, he is likely to return empty. All these cases illustrate that the most small and medium enterprises operate independently and lack of collaboration mechanism ${ }^{[7]}$.

\section{SUGGESTIONS ON THE REFORM OF LOGISTICS IN SMALL AND MEDIUM ENTERPRISES}

\section{A. To establish and improve the internal management system}

Enterprises should first do is to establish and improve enterprise management system, so that employees according to the system, the process of standardized operation. Managers often think that their business is small, not complex, so that do not need to develop operating procedures. There is no standard operating procedures, staff will be changing the practice, there is no tricks, a long time, may cause uncontrollable situation. Therefore, regardless of the size of the enterprise, the work must have the system and process, which is not only the normal operation of the enterprise needs, but also the requirements of the management of information technology.

\section{B. To establish the mechanism of training talents of logistics management}

Market consumption demand are diversified development, and the enterprise can only meet the demand of the consumer by providing competitive products price and high quality service system. High quality service system is mainly reflected in the logistics and distribution links, enterprises want to further improve the service capacity and quality, it is necessary to have a high quality of logistics practitioners to manage.

Small and medium enterprises in the training of personnel according to their own situation, the use of sending out and please come in two ways. Through strengthening cooperation 
with the surrounding schools, the enterprise staff will be sent to the school training, improve staff quality and management capabilities. And management consulting firms, the high quality of modern logistics management personnel hired to work in the enterprise, leading enterprises to standardize the development of modern enterprises on behalf of the road. Of course, enterprises can also be held from time to time the high level of regular logistics training courses, the establishment of a logistics operation demonstration area, nurturing technical backbone, the establishment of management personnel competition mechanism. Only in this way can we really improve the enterprise's logistics level, strengthen the competitiveness of enterprises, so that enterprises in the fierce competition in the market in an invincible position ${ }^{[3]}$.

\section{To establish of logistics management information system for enterprises}

From the production planning, procurement of raw materials to product storage management, are the current logistics management and inventory control more and more diverse and complex, in the past by artificial memory processing, it is difficult to efficiently deal with the existing business. However, if the enterprise cannot guarantee accurate feed, production, quality inspection and timely delivery of accurate, not only cannot let the users satisfy, also because of the low efficiency of enterprises, resulting in unnecessary inventory costs, but also because of delayed delivery and lost the final opportunity for customer service, therefore, enterprises to establish information system modern logistics is essential.

The rapid development of the Internet promoted the growth of the national economy, led to the rapid development of the national economy. For the logistics industry, the society provides a rare opportunity for them, in the development of enterprises, to integrate into the information age. The popularity of smart phones, the improvement of the level of national knowledge, and the rapid development of social economy, smart phones have comprehensive throughout. Therefore, enterprises should also develop app system based on mobile terminals, so that enterprises in the road of information should be fully developed to broaden the channels of information, companies can ultimately reduce operating costs and improve profits.

\section{The national policy support}

At present, China's logistics management policy is not very sound, still need to be improved, the need to introduce relevant policies to keep up with the needs of the logistics industry development. Only a sound logistics management policy, in order to regulate corporate behavior, reduce malicious competition between enterprises, and ultimately guide the healthy development of enterprises on the road of healthy competition.

In addition to the role of the government's macro-control and policy support to promote the healthy and orderly development of the logistics industry, Logistics is a comprehensive service industry involving many industries, which play a decisive role in China's economic construction, should give full play to the role of the government's macrocontrol, and vigorously promote the development of the logistics industry, The development of a comprehensive logistics development planning and the introduction of appropriate measures and support policies, further deepen the logistics industry, industrial recycling, play a logistics industry in reducing costs, improve efficiency and innovative services on the positive role, So as to promote the healthy and orderly development of China's logistics industry.

\section{E. To strengthen cooperation and mutual assistance among enterprises}

To strengthen the cooperation between small and medium enterprises, in addition to the national level of policy guidance, logistics enterprises also spontaneously formed associations to close contact and communication between enterprises, on this basis, to carry out enterprise collaboration, reduce logistics costs as much as possible, for the development of the national economy energy efficiency.

\section{F. Further strengthen the logistics cost accounting, establish a sound cost assessment system}

Logistics cost accounting refers to the use of specialized computing methods, according to the cost of logistics activities identified in the calculation of the object and set the cost of the project, aggregate and distribution of logistics operations in the logistics costs, the unit cost and actual total cost of each costing object are calculated. In the logistics cost accounting, it is necessary to separate from other costs for individual logistics cost accounting, and its accounting content and methods to be clear, and the financial accounting and logistics cost management in the system to effectively link up. At the same time the implementation of cost accounting system should be based on the activities of the relevant costs will be decomposed into the need to consume a certain amount of resources to the activities, rather than decomposed into a department, such a cost accounting system, can make the logistics performance is correct and appropriate evaluation.

\section{SUMMARY}

This paper detailed discusses the status of the development of small and medium-sized enterprise logistics, on the basis of this , analyzes the existing problems and causes of the logistics management in small and medium sized enterprises, finally ,the enterprise existing problems put forward some specific opinions and suggestions. The ultimate purpose of this paper is to hope that our country small and medium enterprises in the development process, the lack of customer service itself, strengthen the enterprise collaboration and mutual assistance, in line with the logistics company as a concept, create a China belongs to the characteristics of the logistics industry system, keep pace with the times, ultimately reducing the logistics cost of small and medium enterprises(SMES), bring more profits at the same time for small and medium enterprises, to contribute to energy-saving society, let our country logistics industry towards a new level. 


\section{ACKNOWLEDGMENT}

This article is an important part of the Huai'an policy guidance project (HAR2015007), in this to the project team members to express my heartfelt thanks!

\section{REFERENCES}

[1] Ouyang Bin. The present status and Countermeasures of logistics management for small and medium sized enterprises[M]. Modern economic information, 2015 (4): 162-163.

[2] Tao Yu. The present situation and thinking of the logistics management of small and medium-size enterprises[M], 2011 (1): 58-60.

[3] Zhu Lijuan. Current situation and thinking of logistics management of small and medium enterprises[M]. Business Herald, 2015 (16): 9-10.
[4] Jitao Mong.The present situation and thinking of the logistics management of the small and medium enterprises[M]. Logistics engineering and management, 2016 (4): 41-42.

[5] Chao Huan. Design of logistics tracking system based on RFID[M]. Electronic technology and software engineering, 2014.8.

[6] Chuan $\mathrm{Ru}$. Some experiences and practices in the construction of logistics centers in foreign countries[M]. Journal of Hunan University(Social Sciences), 2012, 16(3):45-48.

[7] Ningxiang Li. The influence of computer network technology on Logistics Informatization[M]. Digital technology and Applications, 2016.9

[8] Hui Tan, Haining Zhang. Research on the professional talent training model of "3+2" logistics in China and America. Chinese business theory, 2016.9 